\title{
Research Paper: Effectiveness of Social Skills Training on Behavioral Problems in Adolescents with Intellectual Disability
}

\author{
Abbas Nesayan ${ }^{1},{ }^{*}$ Roghaie Asadi Gandomani ${ }^{1}$
}

1. Department of Psychology, Faculty of Humanities Sciences, University of Bojnord, Bojnord, Iran.

citation: Nesayan A, Asadi Gandomani R. [Effectiveness of Social Skills Training on Behavioral Problems in Adolescents with Intellectual Disability (Persian)]. Journal of Rehabilitation. 2016; 17(2):158-167. http://dx.crossref.org/ 10.21859/jrehab-1702158

dof : http://dx.crossref.org/ 10.21859/jrehab-1702158

Received: 28 Jan. 2016 Accepted: 17 Apr. 2016

Keywords:

Adolescents, Intel-

lectual disability, Social skills, Behavioral problems

\section{ABSTRACT}

Objective children and adolescents are faced with wide range of social challengeable situations every day. Intellectual Disability is a condition that determined by significant limitations both in intellectual functioning and in adaptive behavior. This condition occurs before the age of 18 years. The prevalence of intellectual disability is estimated to be at $1-3 \%$ of the total population.

Children and adolescents with intellectual disabilities have deficits in social skills and hence, require social skills training. It is important for students with intellectual disability to make and maintain positive social relationships with family, peers, teachers and other community members.

Social skill training will have the most positive effects on the behavior of students with intellectual disability during the adolescence period. The present study was designed to investigate the effect of social skills on behavioral problems in adolescents with intellectual disability.

Materials \& Methods This was a quasi-experimental research with pretest and posttest and a control group. The study population included 28 adolescents aged 14-16 years with mild intellectual disability in Tehran who were selected using the convenience sampling method. The subjects were randomly assigned into control and experimental groups. The experimental group participated in a training program for 10 sessions. In these sessions, social skills were taught individually. The control group did not receive any social skills training. After this stage, problem behaviors questionnaires were completed by all subjects (control and experimental group). The data obtained was analyzed using descriptive statistics (such as mean, standard deviation and Kolmogorov-Smirnov test for normality of the data) and inferential statistics (such as analysis of covariance).

Results It was found that despite the difference in pre-posttest mean between both the groups, social skills training did not have any significant effect on the behavioral problems of students with intellectual disability ( $P>0.05)$.

Conclusion This research showed that social skills training were not significantly effective on behavioral problems in adolescents with intellectual disability. Although our results were not effective, research evidence shows that people with cognitive delays (such as intellectual disability) require social skill training programs that include all of their academic, career, daily life, and social skills. As social skills learning plays a role in personal and social adjustment, it is necessary to pay more attention to these skills.

\section{* Corresponding Author:}

Roghaie Asadi Gandomani, PhD

Address: Department of Psychology, Faculty of Humanities Sciences, University of Bojnord, Bojnord, Iran.

Tel: +98 (583) 3201000

E-Mail: r.asadi@ub.ac.ir 


\title{
اثربخشى أموزش مهارتهاى اجتماعى بر مشكلات رفتارى نوجوانان با كمتوانى ذهنى
}

\author{
عباس نسائيان'، "رقيه اسدى كندمانى' \\ 1- كروه روانشناسى، دانشكده علوم أنسائى، دانشعًاه بجنورد، بجنوردء ايران.
}

\begin{abstract}
حكبد

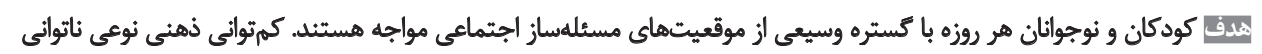

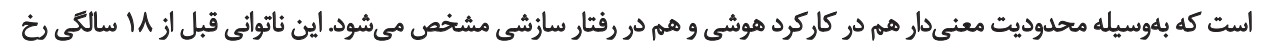

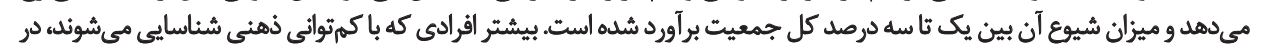

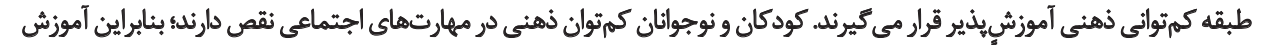

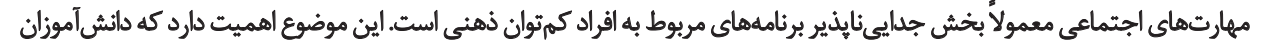

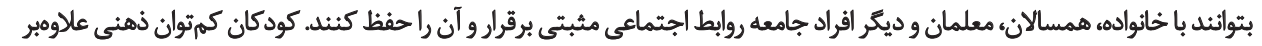

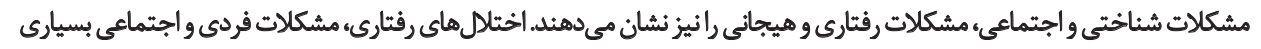

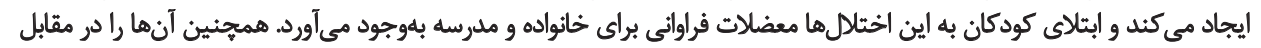

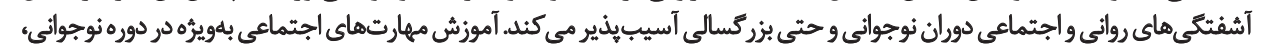

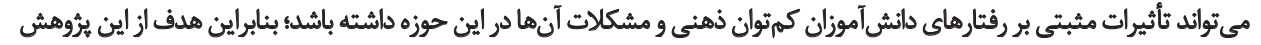

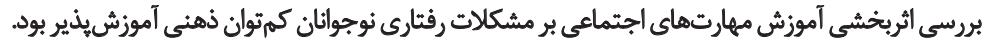

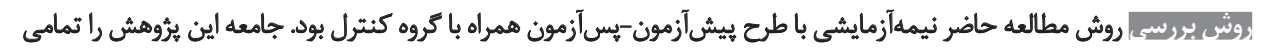

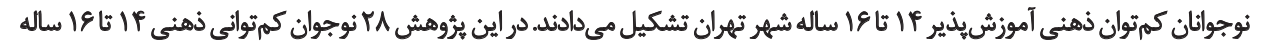

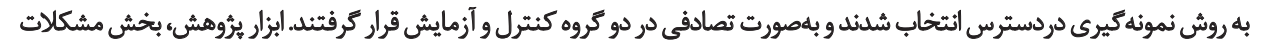

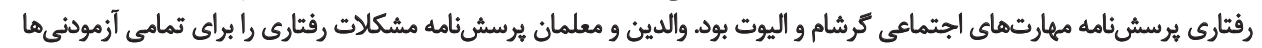

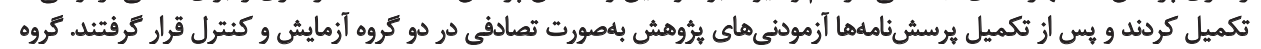

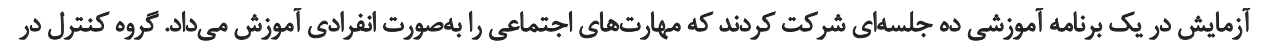

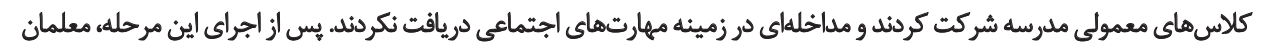

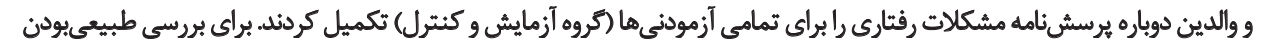

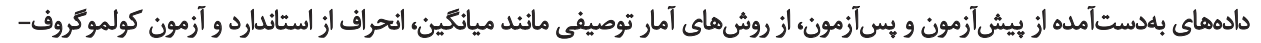

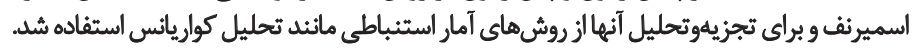

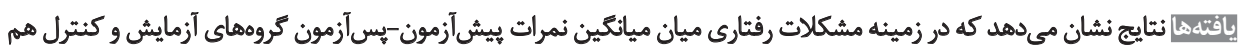

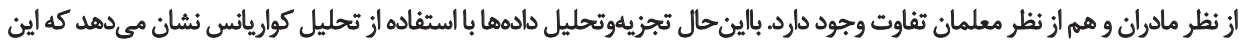

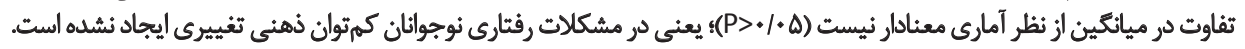

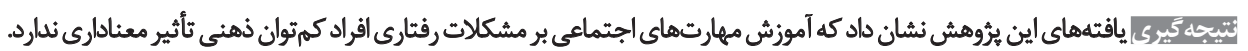

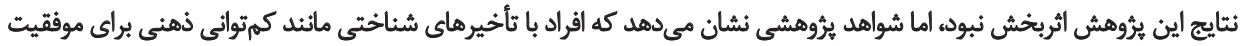

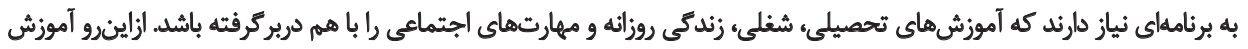

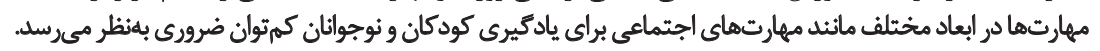

تاريخ دريافت: A بهيمن 4

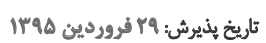

كليدواروها:

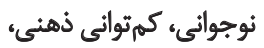

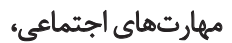

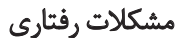


فعاليتهاى اوقات فراغتشان در خانه كم است و ونسبت به كسانى

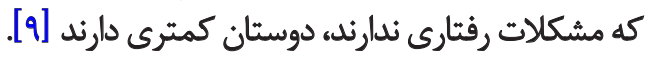

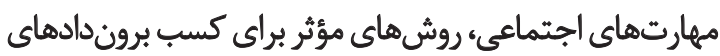

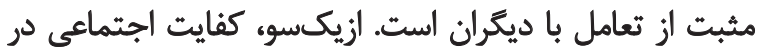

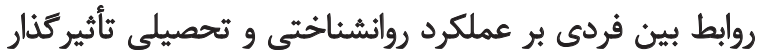

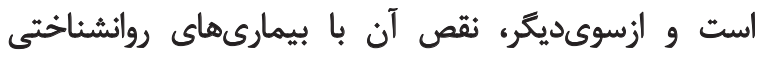

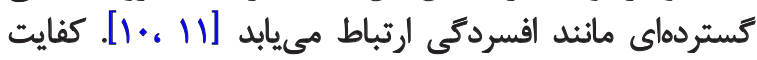

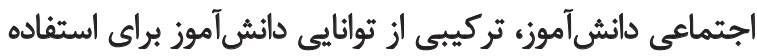

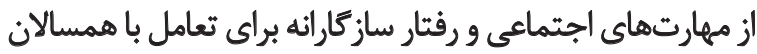

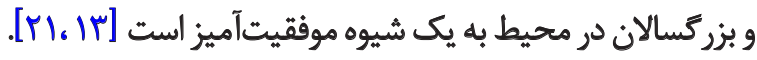

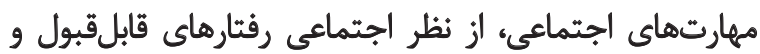

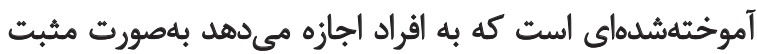

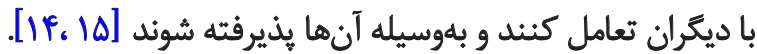

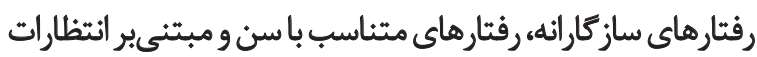

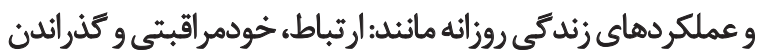

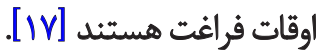

كودكان با كمثوانى ذهنى در مقايسه با همتايان عادى خود از

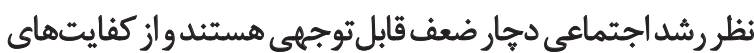

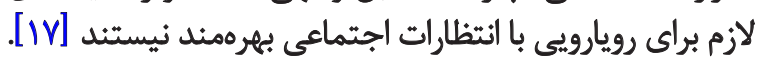

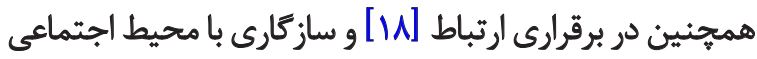

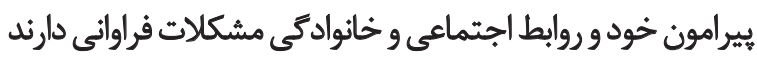

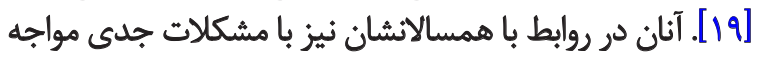

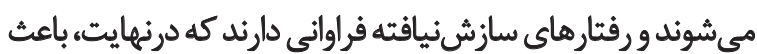

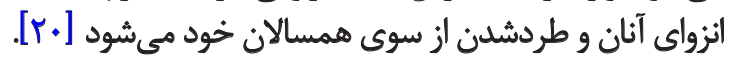

اين كودكان بيش از كودكان عادى از تعامل با دوستان برهيز

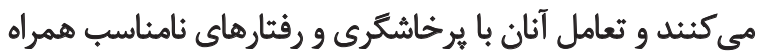

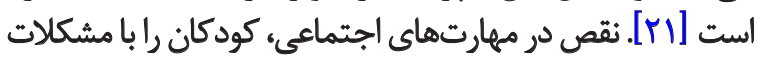

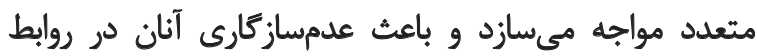

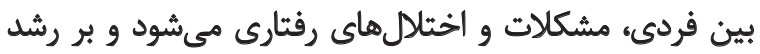

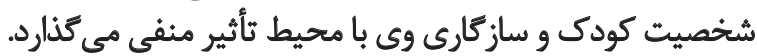

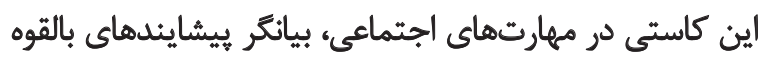

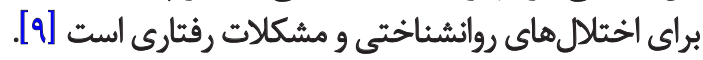

ارتقاى رفتار اجتماعى افراد با كمتوانى ذهنى براى مداى مدتهاست

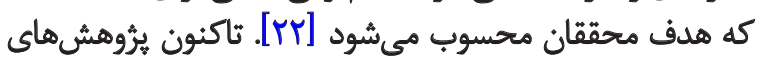

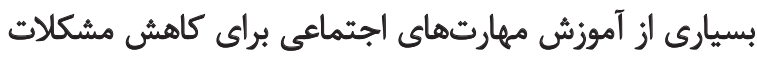

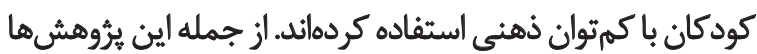

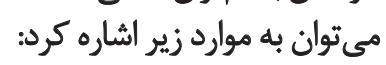

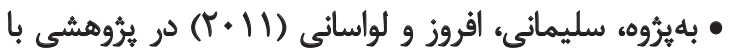

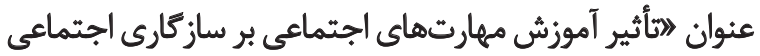

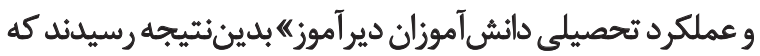

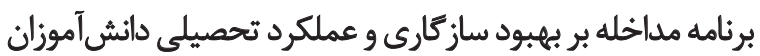

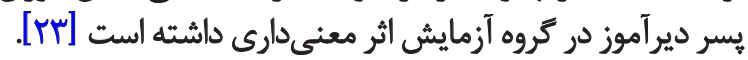

مقدمه

در جوامع بشرى امروزى كمتوانى ذهنى يكى از عمدهترين،

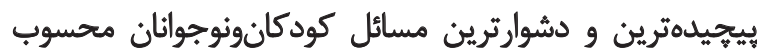

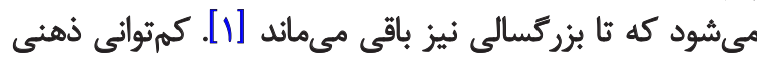

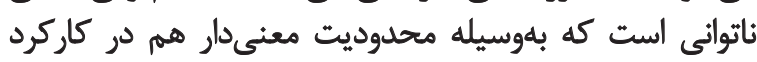

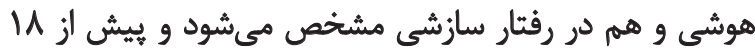

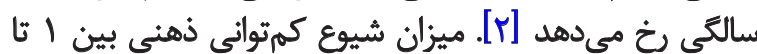

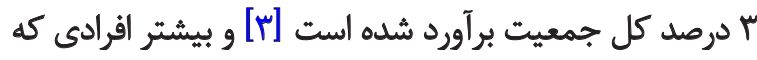

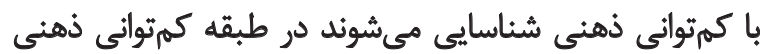

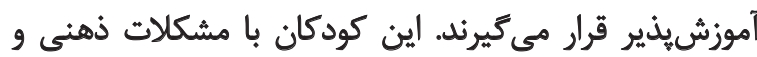

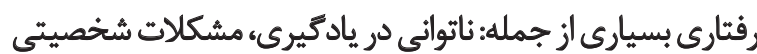

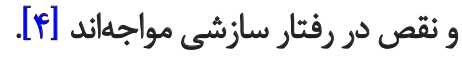

كودكان با كمتوانى ذهنى علاومبر مشكلات شناختى و

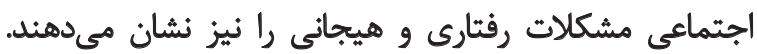

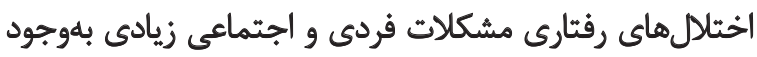

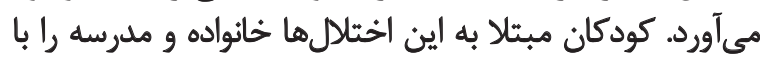

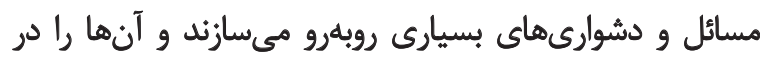

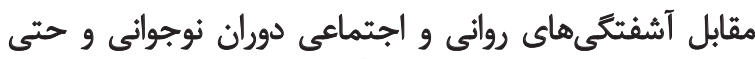
بزركسالى آسيبيذير مي كنئد [هاني

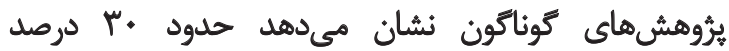

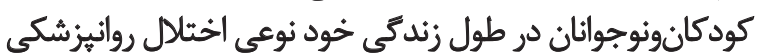

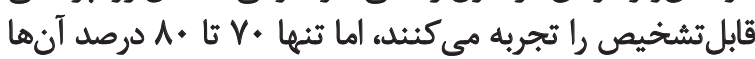

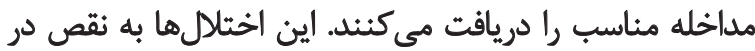

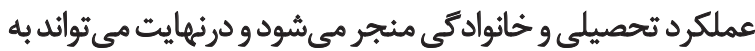

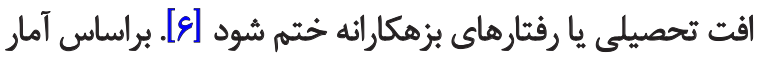

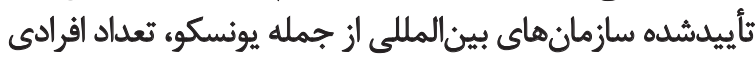

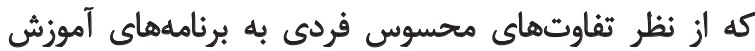

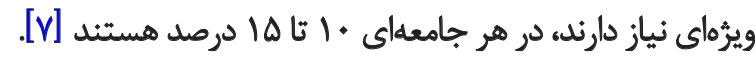

كودكان با كمرتوانى ذهنى به سبب مشكلات كوناتياكون ناشى از

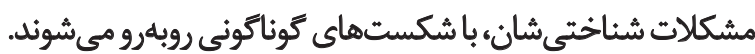

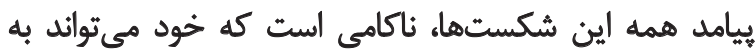

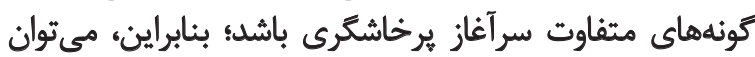

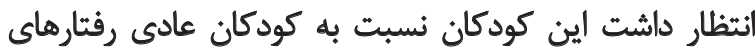

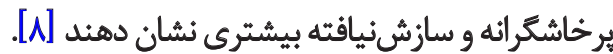

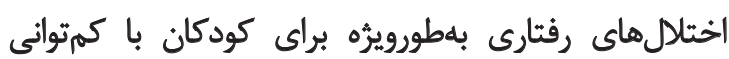

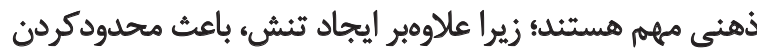

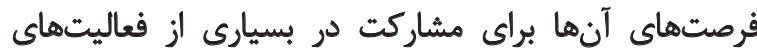

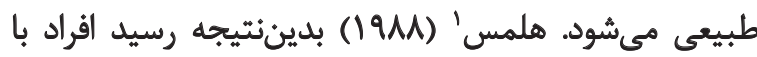

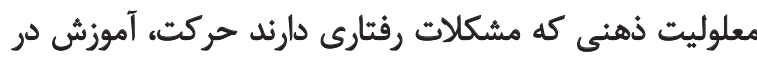

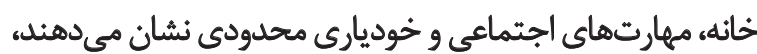

1. Holmes 
آموزشى ديكر. ملاكهاى خروج از مطالعه نيز شامل وجود

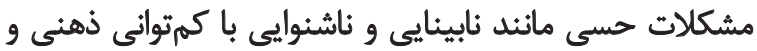

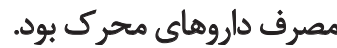

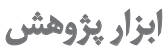

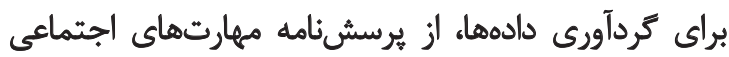

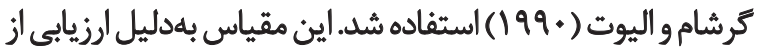

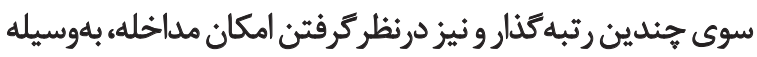

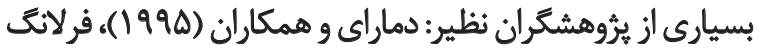

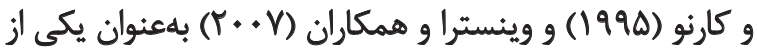

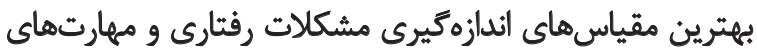

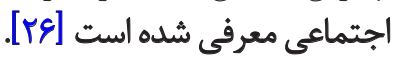

مقياس مهارتهاي اجتماعى شامل سه فرم ويرٔه ارزيابي توسط

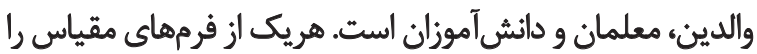

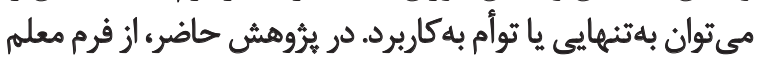

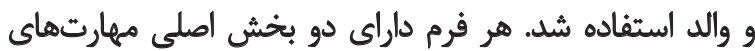

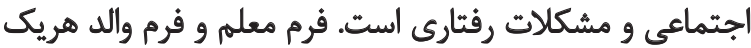

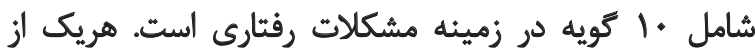

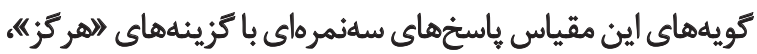

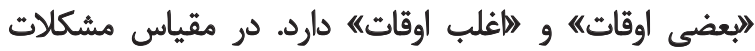

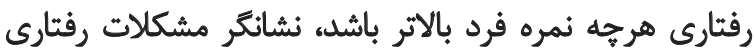

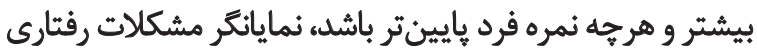

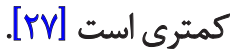

در زمينه بررسى ثايايى و روايى مقياس درجهبندى مهارتهاي

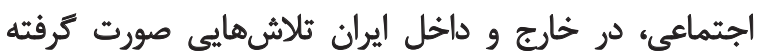

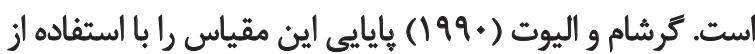

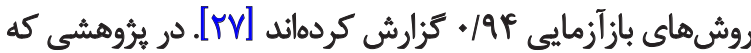

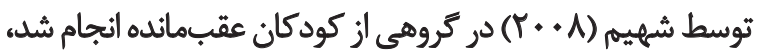

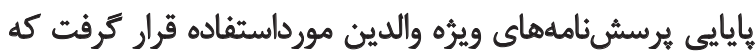

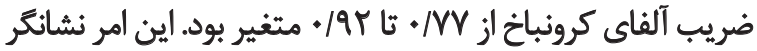

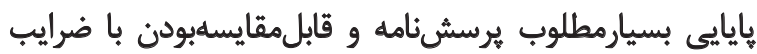

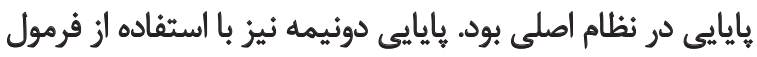

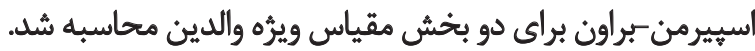

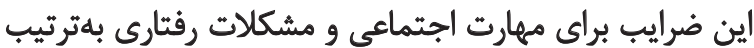

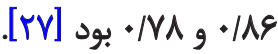

$$
\text { وش اجمرا }
$$

يس از كسب مجوزهاى لازم از سازمان آموزشويروش

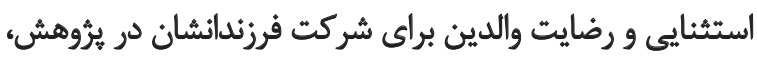

مراحل اجراى يروهش در كامهايى بهشرح زير انجام شد:

• كام اول (يبشآزمون): در اين مرحله براي كليه نوجوانان

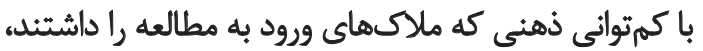

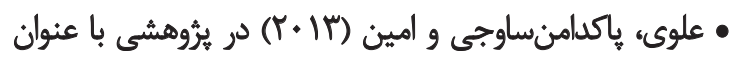

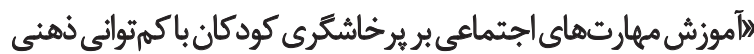

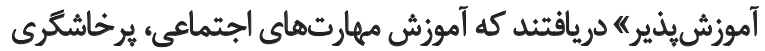

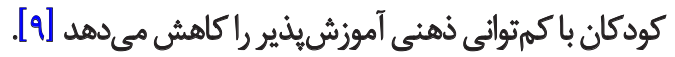

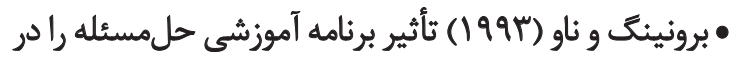

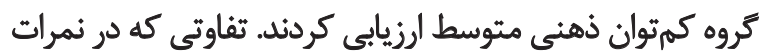

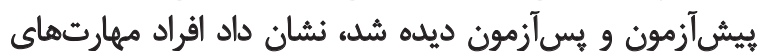

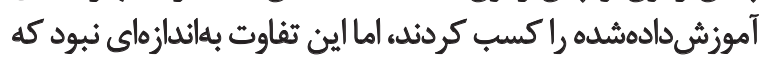
تفاوت معنادارى بلوجود آورد.

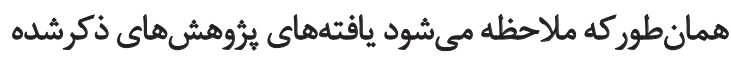

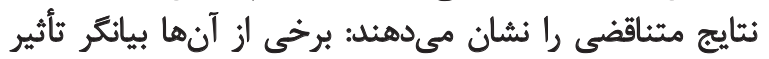

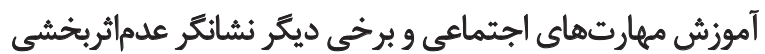

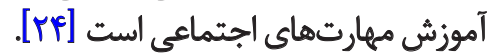

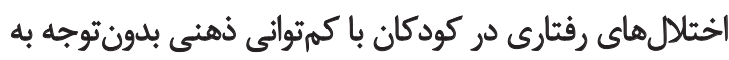

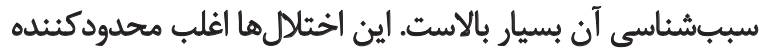

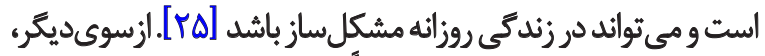

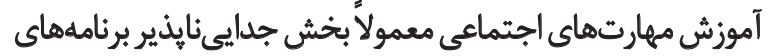

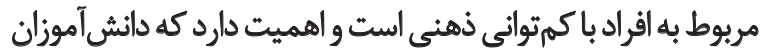

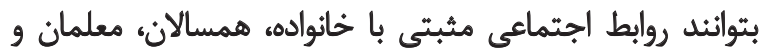

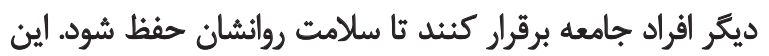

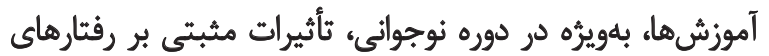

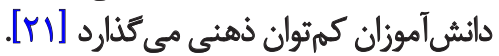
ازيكسو، وجود مشكلات رفتارى و اهميت آموزش مهارتهاي

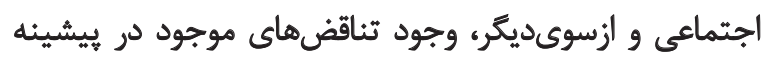

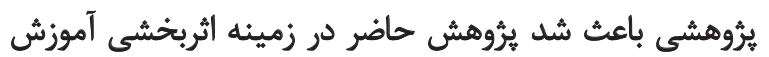

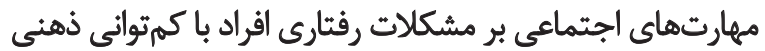

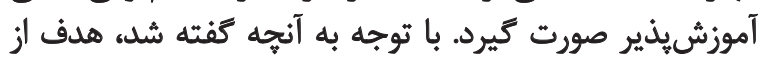

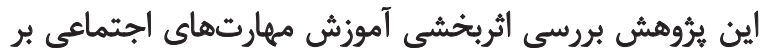

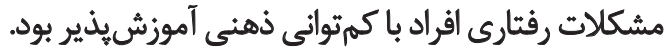

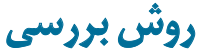

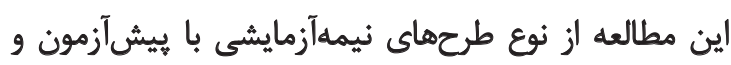

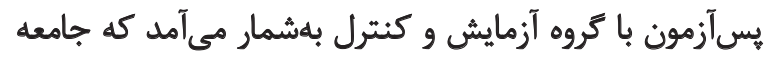

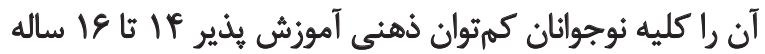

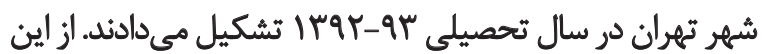

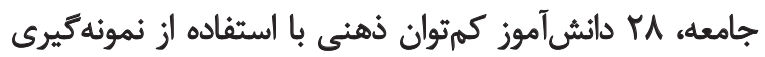

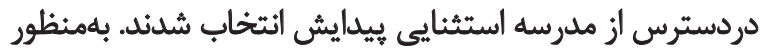

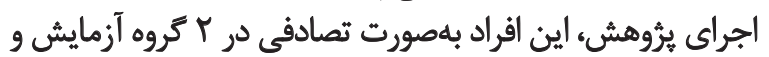
كنترل قرار داده شدئد.

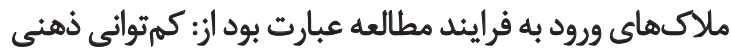

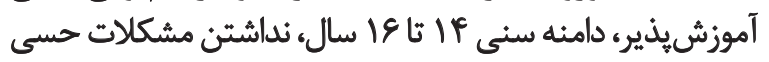

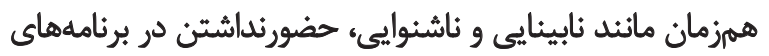


جدول ا. مراحل استخراج دادههاى خام.

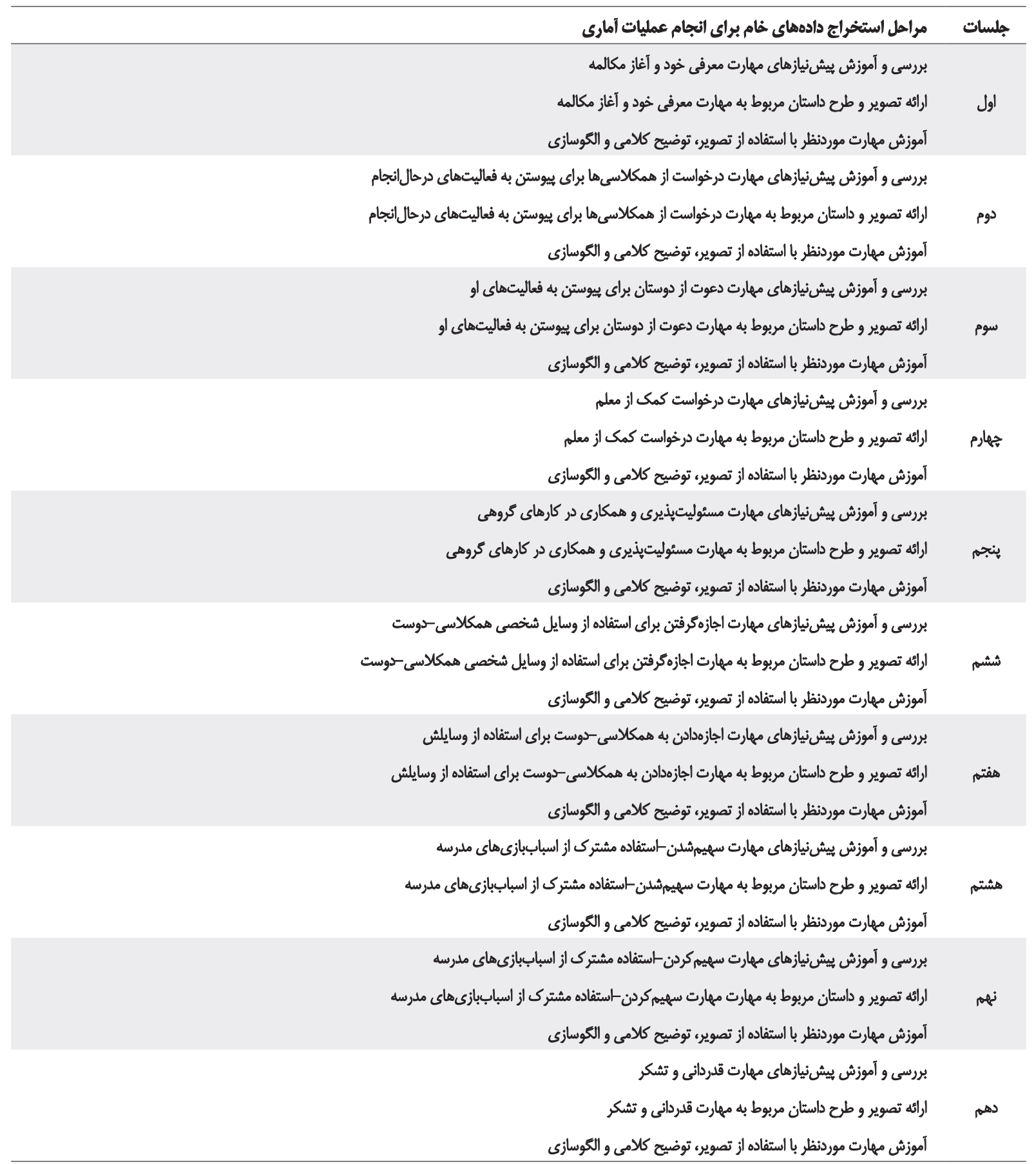

توانبخننى

انتخابشده بلهورتصادفى در دو كروه آزمايش و كروه كنترل قرار كرفتئد.

• كام جهارم (آموزش): در اين مرحله بهطورائفرادى به كروه

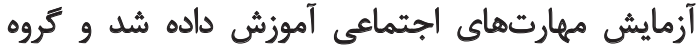

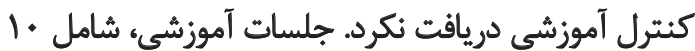

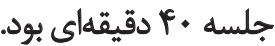

يرسش نامه كرشام و اليوت توسط معلم و والدين تكميل شد.

• كام دوم: در اين مرحله افرادى كه نمرههاي بالايبي در

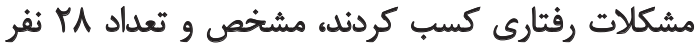
براى شركت در مطالعه انتخاب شدئد. • كام سوم: يس از انتخاب آزمودنئهاء در اين مرحله افراد 
قرار كرفت كه حداقل ه سال سابقه كار با اقراد با كمتوانى ذهنى

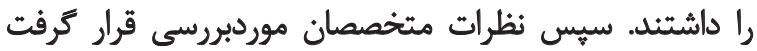

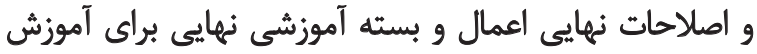

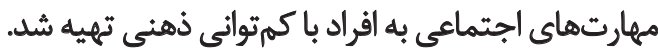

Ldiọ

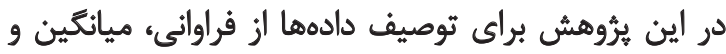

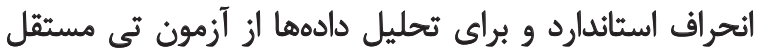

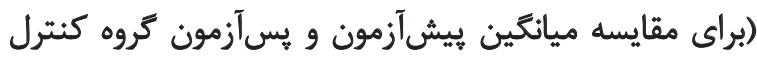

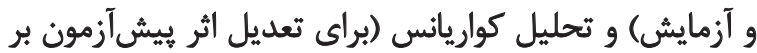

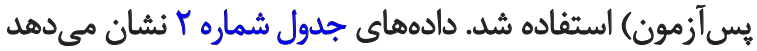

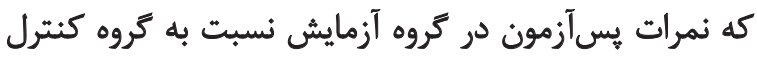

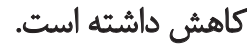

قبل از انجام تحليل كواريانس مفروضههاى آن موردبررسى

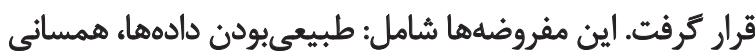

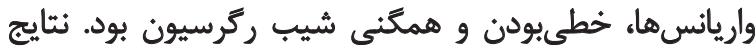

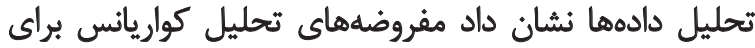

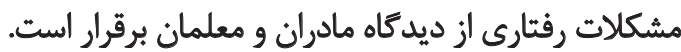

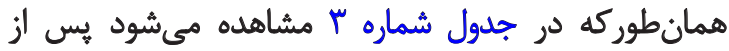

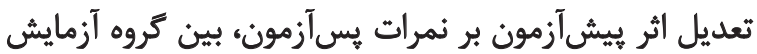

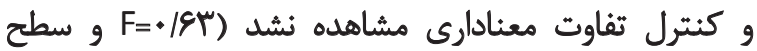

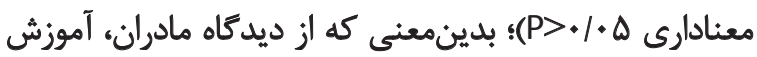

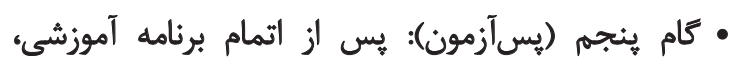

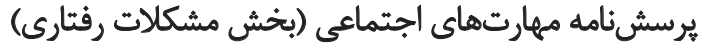

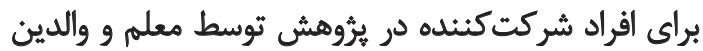

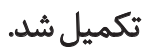

• • كام ششم: در اين مرحله دادههاي خام براى انجام عمليات

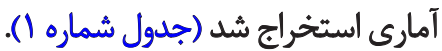

$$
\text { برنامه آموزشيى }
$$

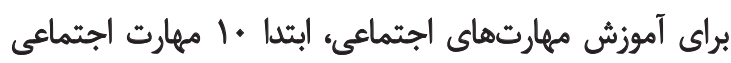

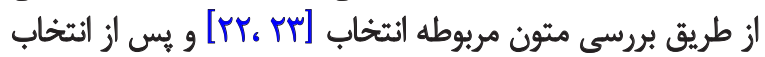

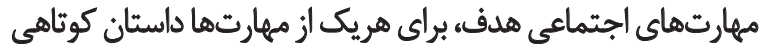

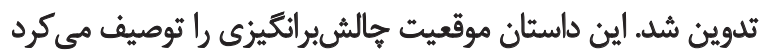

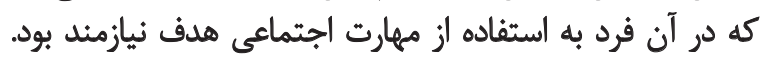

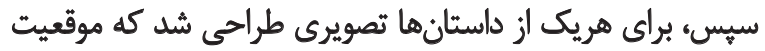

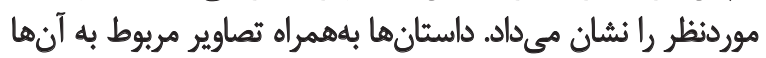

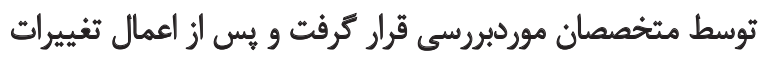

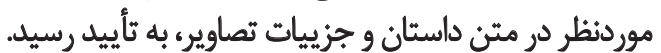
با توجه به اينكه داستانها و تصاوير براى طيف خاصى از افراد

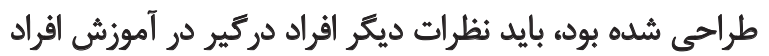

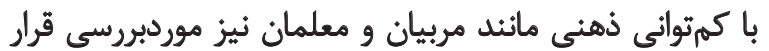

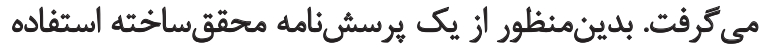

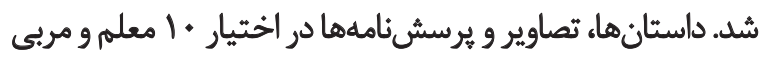

جدول r. مقايسه بيشآزمون و بسآزمون مشكلات رفتارى در مروه آزمايش و كنترل.

\begin{tabular}{|c|c|c|c|}
\hline انحراف از استاثدارد & مياتكين & تمروه & متغير \\
\hline $\begin{array}{l}\text { سT/T } \\
\end{array}$ & $\begin{array}{l}\text { 9/1\% } \\
1 .\end{array}$ & أزمايش & ييش آزمون والدين \\
\hline $\begin{array}{l}r / \Delta F \\
r / 19\end{array}$ & $\begin{array}{l}\text { NTA } \\
\text { NTA }\end{array}$ & آزمايش & ييشأزمون معلمان \\
\hline $\begin{array}{l}\mathrm{W} / \mathrm{A} \\
\mathrm{r} / \mathrm{F}\end{array}$ & $\begin{array}{l}9 / \mathrm{V} \\
N \times \Delta\end{array}$ & كنترل & يس آزّمون والدين \\
\hline $\begin{array}{l}r / \Delta Q \\
r / Q V\end{array}$ & $\begin{array}{l}\text { V/AY } \\
V / A F\end{array}$ & أزمايش & يسأزهون هعلمان \\
\hline
\end{tabular}

توانبخننى

جدول "ا. نتايج تحليل كواريانس براى تعيين اثربخشي آموزش مهارتهاى اجتماعى بر مشكلات رفتارى با كنترل متغير مشكلات رفتارى بيش آزمون (مادران).

\begin{tabular}{|c|c|c|c|}
\hline P-value & $\mathbf{F}$ & مجموع مجذورات & منايع تغييرات \\
\hline$+1 . .+1$ & re/aY & ITV/Na & هشكلات رقتتارى ييش أزهون \\
\hline \multirow[t]{3}{*}{.$/ 4 r s$} & . & $r / T r$ & اثر اصلى (أموزش) \\
\hline & & NIAS & خطاى باقىمائده \\
\hline & & wor & مقيدار كل \\
\hline
\end{tabular}


جدول f. نتايج تحليل كواريانس براى تعيين اثربخشى آموزش مهارتهائ اجتماعى بر مشكلات رفتارى با كنترل متغير مشكلات رفتارى بيشآزمون (معلمان).

\begin{tabular}{|c|c|c|c|}
\hline مقدار احتمال & $\mathbf{F}$ & مجموع مجذورات & مثابع تغييرات \\
\hline.$/ 11 \Delta$ & $.1 . \Delta$ & .1198 & مشكلات رفتارى يش آزمون \\
\hline \multirow[t]{3}{*}{. $/ 4 F \Delta$} & .191 & $9 / \pi$ & اثثر اصلى (آموزش) \\
\hline & & 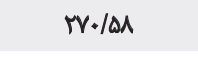 & خطاى باقى مائده \\
\hline & & $10 .$. & مقدار كل \\
\hline
\end{tabular}

توانبخننى

را كاهش ميدهد [F]. كريمي، كيخاونى و محمدى (11)

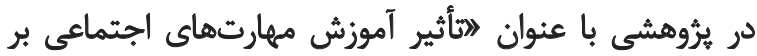

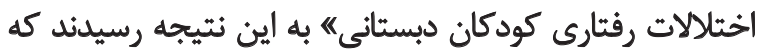

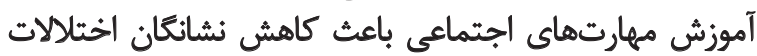

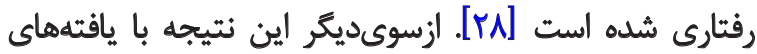

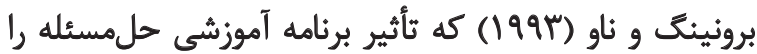

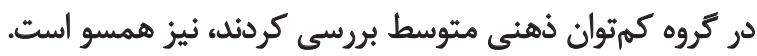

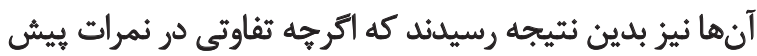

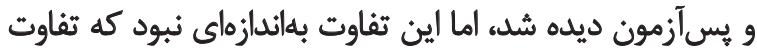

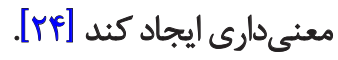

شايد بتوان تناقض هاى يُوهشى رابامتفاوتبودن جوامع،نمونه،

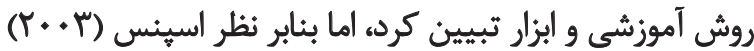

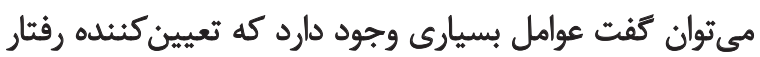

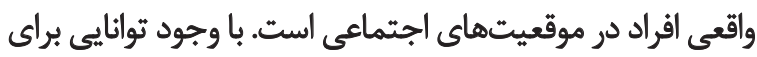

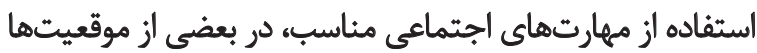

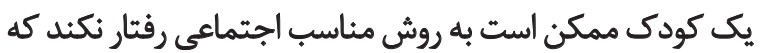

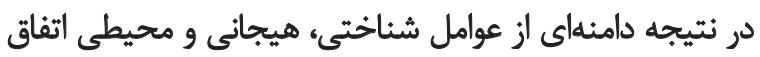

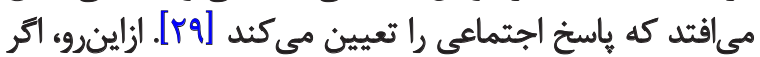

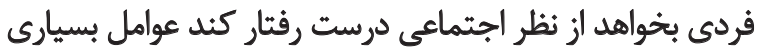
مانند عوامل شناختى، هيجانى و محيطى لازئ درم است

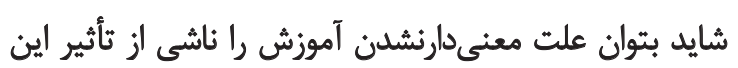

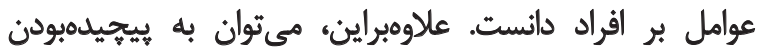

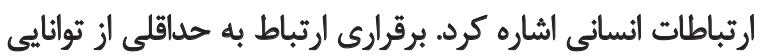

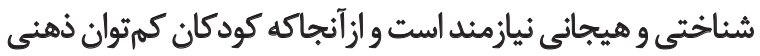

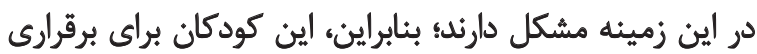

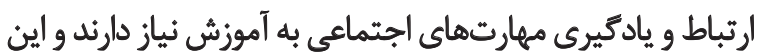

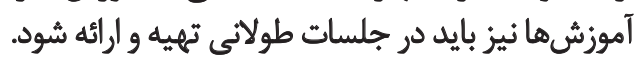

\section{نتيجليَيرى}

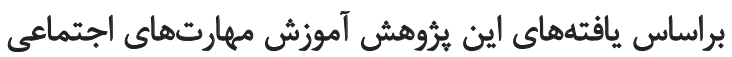

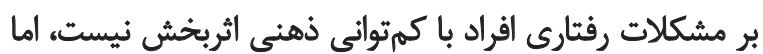

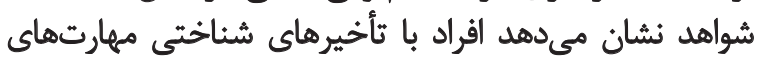

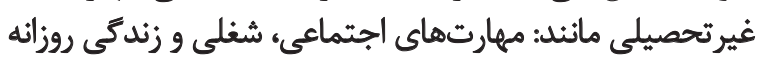

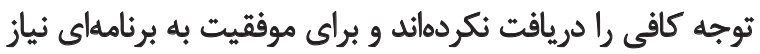

مهارتهاي اجتماعى بر مشكلات رفتارى نوجوائن با كمثتوانى ذهنى ثأثير معنى الرى نداشى بر مثكلات است.

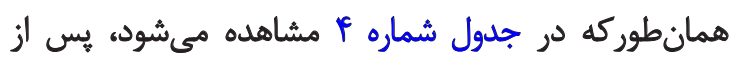

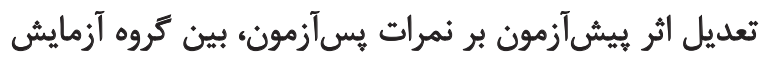

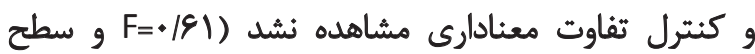

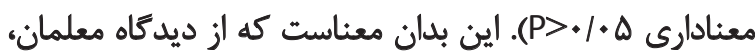

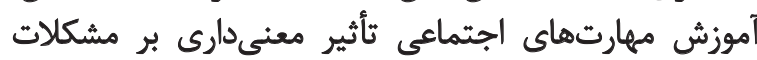

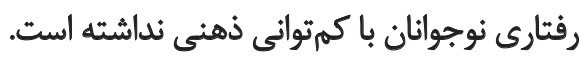

ب़

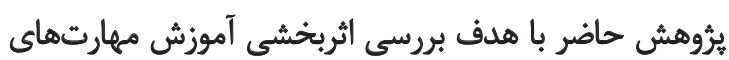

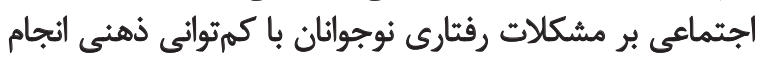

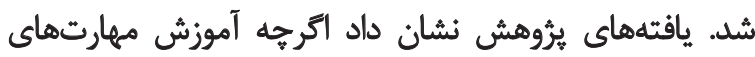

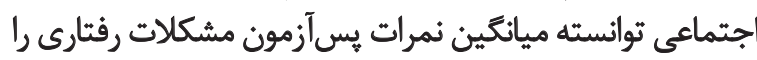

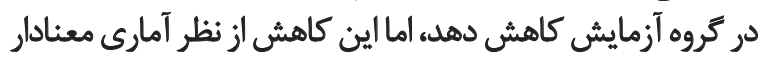

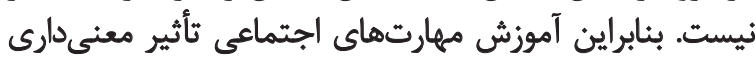

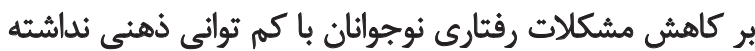

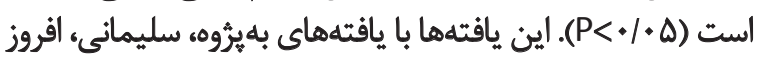

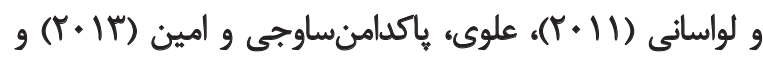

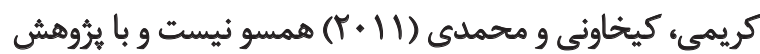

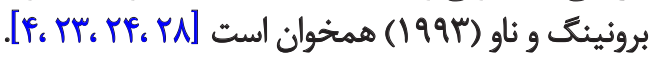

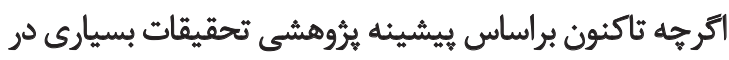

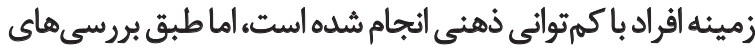

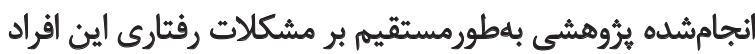

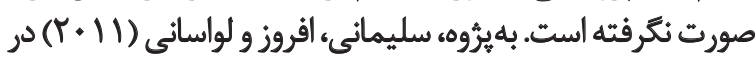

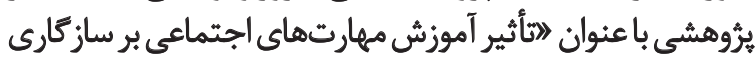

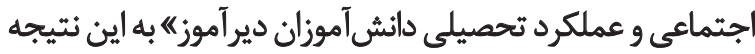

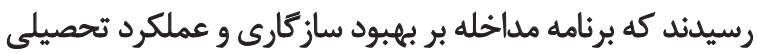

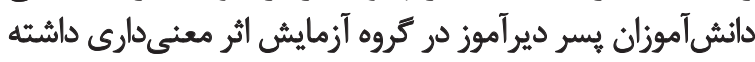

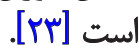

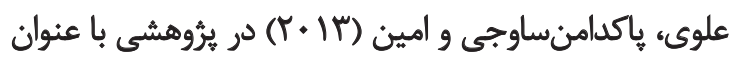

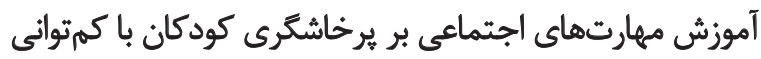

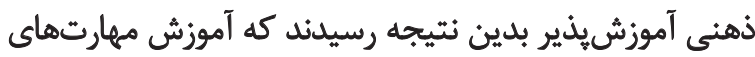

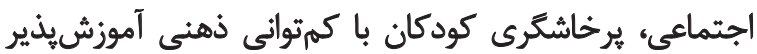




\section{References}

[1] Mohammad khan Kermanshah S, Vanaki Z, Ahmadi F, Azad Fallah P, Kazemnejad A. [Experiences of mothers of mentally retarded children (Persian)]. Journal of Rehabilitation. 2006; 7(3):26-33.

[2] Kirk S, Gallager J, Coleman MR. Education exceptional children. Boston: Cengage Learning; 2015.

[3] Akhavast A, Bahrami H, Pourmohamadreza-Tajrishi M, Biglarian A. Instructional games effect on learning of some mathematics concepts in boy students with educable mentally retarded (Persian)]. Journal of Rehabilitation. 2008; 10(3):18-28.

[4] Alavi S. Z, Pakdaman Savoji A, Amin F. The effect of social skills training on aggression of mild mentally retarded children. Social and Behavioral Science. 2013; 84:1166-170.

[5] Seife A. [Theories of behavioral therapy and behavior modification (Persian)]. Tehran: Dowran Publication; 2008.

[6] Azar Niushan B, Behpazho A, Ghobari B. [The effect of play therapy with cognitive-behavioral approach on behavioral problem in student with intellectual disability in elementary school (Persian)]. Iranian Exceptional Children Journal. 2012; 2(44):5-16.

[7] Soleimani M, Abdi K, Mousavi Khatat M. [Comparing demographic characteristics and the biological parents of children over one exceptional children with parents of normal children (Persian)]. Journal of Rehabilitation. 2011; 11(1):94-104.

[8] Afrooz Gh. [Psychology and education of exceptional children. (Persian)]. Tehran: University of Tehran Publication; 2009.

[9] Prakash J, Sudarsanan S, Prabhu HR. Study of behavioural problems in mentally retarded children. Delhi Psychiatry Journal. 2007; 10(1):40-45.

[10] Cook CR, Gresham FM, Kern L, Barreras RB, Thornton S, Crews S. Social skills training for secondary students with emotional and/or behavioral disorders: a review and analysis of the meta-analytic literature. Journal of Emotional \& Behavioral Disorders. 2008; 16(3):131-44.

[11] Gresham FM, Elliot SN. Social skills rating system. Circle Pines, MN: American Guidance Services; 1990.

[12] Esser TH. The impact of prolonged participation in a pro-social cognitive behavioral skills program on elementary age students, with behavior related disorders, behavior accelerative, behavior reductive, and return to regular classroom outcomes [ $\mathrm{PhD}$ thesis]. Nebraska-Lincoln: Nebraska University; 2012.

[13] Meadan H, Monda-Amaya L. Collaboration to promote social competence for students with mild disabilities in the general classroom: a structure for providing social support. Intervention in School \& Clinic. 2008; 43(3):158-67.

[14] Epstein MH, Cullinan D, Ryser G, Pearson N. Development of a scale to assess emotional disturbance. Behavioral Disorders. 2002; 28(1):5-22.

[15] Gresham FM, Vance MJ, Elliott SN, Cook CR. Comparability of the social skills rating system to the social skills improvement system: content and psychometric comparisons across elementary and secondary age levels. School of Psychology Quarterly. 2011; 26(1):27-44.

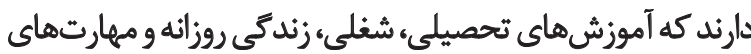

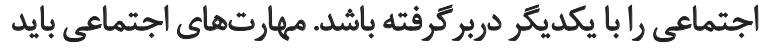

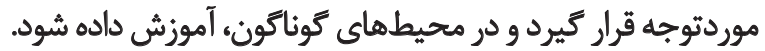

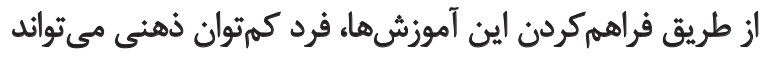

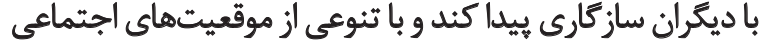

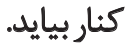

$$
\begin{aligned}
& \text { بيشئهادها }
\end{aligned}
$$

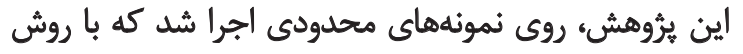

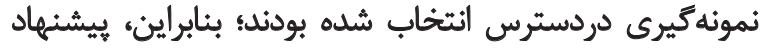

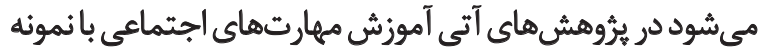

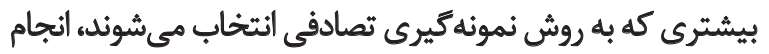

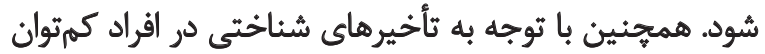

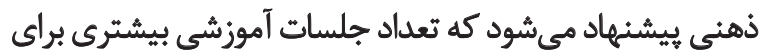

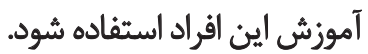

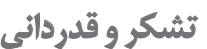
مقاله حاضر از حامى مالى بىبهره بوده است. 
[16] Lee HJ, Park HR. An integrated literature review on the adaptive behavior of individuals with Asperger Syndrome. Remedial and Special Education. 2007; 28(3):132-39.

[17] Emerson E. Prevalence of psychiatric disorders in children and adolescents with and without intellectual disability. Journal of Intellectual Ability Research. 2003; 47(1):51-69.

[18] Elliot SN, Gresham FM, McCloskey G. Teachers and observers ratings of children's social skills: validation of social skills rating scales. Journal of Psychoeducational Assessment. 1998; 6(2):15261.

[19] Barkely RA. Attachment-deficit hyperactivity disorder. In: Mash EJ, Barkely RA, editors. Child Psychopathology. $2^{\text {nd }}$ ed. New York: Plenum Press; 2003, p. 75-143.

[20] Gezli MD, Pier JM. Social incompetence in children with ADHD: possible moderators and mediators in social skills training clinical psychology review. Journal of Personality and Social Psychology. 2007; 27(1):78-97.

[21] Liu X. Behavioral and emotional problems in Chinese children with mental retardation and without intellectual disability. Journal of American child and Adolescence Psychiatry. 2000; 30(7):869903.

[22] Crites SA, Dunn C. Teaching social problem solving to individuals with mental retardation. Education and Training in Developmental Disabilities. 2004; 39(4):301-09.

[23] Behpazhoh A, Soleymani M, Afroz Gh, Lavasani MGh. [Effectiveness of social skills training on social adjustment and academic performance in intellectual disability student (Persian)]. Journal of Educational Innovations. 2011; 23(9):163-86.

[24] Browning P, White W. Teaching life enhancement skills with interactive video-based curricula. Journal of Education and Training of the Mentally Retarded. 1986; 21(4):236-44.

[25] Ageranioti-Bélanger S, Brunet S, D’Anjo G, Tellier G, Boivin J, Gauthier M. Behaviour disorders in children with an intellectual disability. Pediatric Child Health. 2012; 17(2):83-88.

[26] Shahim S. [Social skills in children with mental retardation based of social skills rating scale (Persian)]. Journal of Psychology and Education. 2008; 4(1):18-37.

[27] Shahim S. [Validity and reliability of social skills rating scale in preschool children, (Persian)]. Iranian Journal of Psychology and Clinical Psychology 2005; 41(2):176-86.

[28] Karimi M, Kikhavani S, Mohamadi MB. [Effectiveness of social skills training on behavioral disorders in elementary school (Persian)]. Journal of Ilam University of Medical Sciences. 2011; 18(3):61-68.

[29] Spence SH. Social skills training with children and young people: theory, evidence and practice. Child and Adolescent Mental Health. 2003; 8(2):84-96. 
